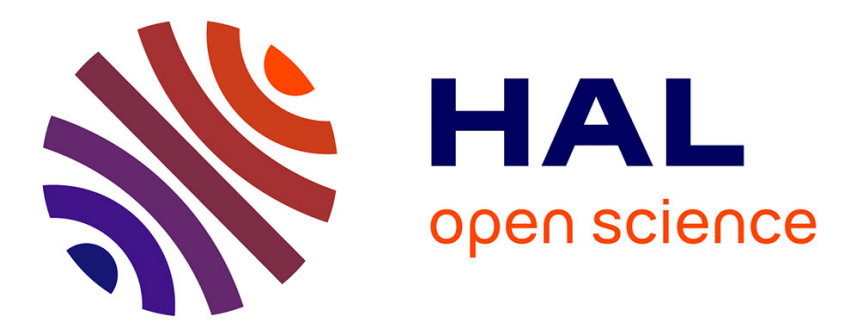

\title{
The impact of herpes zoster and subsequent chronic pain on patients' daily lives
}

Benoit Arnould, Khadra Benmedjahed, Jean-Luc Gallais, Patrick Giniès, Ralf Baron

\section{- To cite this version:}

Benoit Arnould, Khadra Benmedjahed, Jean-Luc Gallais, Patrick Giniès, Ralf Baron. The impact of herpes zoster and subsequent chronic pain on patients' daily lives. Journal of Public Health, 2010, 18 (6), pp.567-574. 10.1007/s10389-010-0346-6 . hal-00551210

\section{HAL Id: hal-00551210 https://hal.science/hal-00551210}

Submitted on 3 Jan 2011

HAL is a multi-disciplinary open access archive for the deposit and dissemination of scientific research documents, whether they are published or not. The documents may come from teaching and research institutions in France or abroad, or from public or private research centers.
L'archive ouverte pluridisciplinaire HAL, est destinée au dépôt et à la diffusion de documents scientifiques de niveau recherche, publiés ou non, émanant des établissements d'enseignement et de recherche français ou étrangers, des laboratoires publics ou privés. 
Editorial Manager(tm) for Journal of Public Health Manuscript Draft

Manuscript Number: JOPH-D-09-00070R1

Title: The impact of herpes zoster and subsequent chronic pain on patients' daily lives

Article Type: Original Article

Corresponding Author: Dr Benoit Arnould,

Corresponding Author's Institution: Mapi Values

First Author: Benoit Arnould

Order of Authors: Benoit Arnould; Khadra Benmedjahed, BA; Jean-Luc Gallais, MD; Patrick Giniès, MD; Ralf Baron, MD

Abstract: Aim: The aim of our study was to carry out a literature review and develop a model illustrating the domains of patients' lives that are impacted by herpes zoster (HZ) and subsequent chronic pain.

Subject and Methods: Biomedical databases and online congress archives were searched using keywords related to $\mathrm{HZ}$ or post-herpetic neuralgia (PHN) and social, psychological or physical impact. 733 abstracts were reviewed. 29 publications containing concepts reported by patients were retained for the model. Wilson and Cleary's Model was used to organise the findings. Links between concepts were documented on three levels; hypothesis, observation and evidence. The final model illustrates the concepts impacted by HZ and PHN, relationships between these concepts and the level of evidence identified.

Results: The concepts identified from the articles were grouped into the following categories:

Biological/Physiological, Symptom Status, Functional Status, Health Perceptions, Characteristics of the Individual, Health-Related Quality of Life (HRQOL), Treatment and Characteristics of the Environment. Evidence exists that HZ-related pain directly impacts Functional Status, Health Perceptions and HRQOL. Conclusion: Patients report that all major domains of life are impaired by HZ or subsequent chronic pain. HZ and its painful and debilitating complications can have a substantial impact on physical, psychological, social and role functioning, HRQOL and activities of daily living. The impact on elderly patients needs to be further assessed with appropriately designed and validated instruments, with specific attention paid to dependence.

Response to Reviewers: Lyon, 30 March 2010

Wilhem Kirch

Editor-in-chief, Journal of Public Health

Ref: Ms. No. JOPH-D-09-00070, "The impact of herpes zoster and subsequent chronic pain on patients' daily lives"

Dear Editor, 
Thank you and the reviewers for your feedback on our manuscript, "The impact of herpes zoster and subsequent chronic pain on patients' daily lives".

Attached is our revised manuscript based on the reviewers' comments: we joined a version of the manuscript with track changes, and the manuscript with these changes accepted. Below we provide our point-by-point responses to these comments.

Reviewer \#1:

"Herpes zoster and the painful complication PHN have a severe impact on patient's quality of life. Due to the actual discussion on the prophylaxis of VZV, I really sympathize with this very good review of the literature. Although the mass of information provided is difficult to digest, it is really helpful for the present discussion. This manuscript helps to have hard data in a subject which we already seem to know; this review puts the focus on the complications caused by VZV and their impact on patients' daily lives.

I recommend to accept the paper and see no need for a revision."

We have slightly restructured the manuscript and added section titles. This will likely facilitate the reading of this dense manuscript.

Reviewer \#2:

"The authors investigate the impact of zoster and pain following virus infection on patient's daily activities using international database search. The abstract and article selection process is described sufficiently. In addition to this method two models were calculated (description and causal model). As results the authors outline domains and general concepts corresponding to references identified by a simple figure (for descriptive model). The same method is used for the so-called causal model. The results obtained are not unexpected. In terms of discussion and conclusion the reviewer is missing the central threat:

1. "The line of thoughts is jumping a little bit around from one subject to another (e. g. page 9/10 row 18-34 and row 1-4 clearly is a repetition of point 'Assessment of evidence level and development of the causal model'). Therefore it should be cancelled."

As suggested, we removed the lines that were a repetition of "Assessment of evidence level and development of the causal model".

In parallel, we restructured this paragraph in order to better outline the points of discussion and to avoid repetitions with the "Methods" section.

2. "Moreover, a part of discussion is dealing with limitations (e. g. quality of life, page 10, row 5-13). In general, this explanation is correct, but the position should be placed at the beginning or at the end." We placed the section about quality of life at the end of the "Discussion and conclusion" section, as advised.

3. "The term 'pain' is discussed on page 10 row 15-34. This thoughts are interrupted by 'unmet need' from row 8-13 and direct costs and so on. On row 15 the authors repeatedly are discussing the issue 'pain'."

We restructured this part of the manuscript in order to keep and discuss only the concepts and associations that were identified in the descriptive and causal models.

In addition, in regards to the reviewer's concern about the length of the manuscript, we removed lines throughout this part (Page 10, lines 17-29; page 11, lines 2-4, 9-12) and relocate them in the "Results" section, where they support and facilitate the reading of the figures that are proposed. Also, we have made some changes: the revised discussion is now structured so that there is a brief introduction and summary of what has been done during the work, the rationale and the main result (Page 9, lines 3-21); then the place of 'pain' and the other concepts identified in the descriptive model and the impact 
represented in the causal model (Page 9, lines 23-32; page 10, lines 1-9); pain and therapeutic strategy (Page 10, lines 11-24); the instruments available (Page 10, lines 26-34); the additional research that should be done and the main limitation of the work (Page 11, lines 1-19). We hope this will help the reader to get to the critical points of the work more easily.

4. "Finally, to make a long story short: The discussion should be outlined more systemically especially in terms of separation between methodological and specialized issues. Redundancies should be eliminated. Regardless of the critical points the manuscript should be shortened substantially." As suggested, we shortened the manuscript, especially the "Discussion" section (initially, 1,500 words; currently: 1,000 words) where redundancies have been removed. We restructured the paragraphs of the discussion and relocated result parts in its respective section to better outline and highlight the critical points. We have added titles in the "Methods" and "Results" sections, which should also contribute to a higher clarity and ease of reading.

We took into consideration the points raised above and revised the manuscript accordingly to reinforce the comprehension and strength of the paper and its discussion, and to shorten it to help readers go to the point.

We hope that the revisions and answers to your questions and comments meet your expectations, and that you will consider our revised manuscript for publication. Should you need more information or have question, please do not hesitate to contact us.

Yours sincerely,

Benoit Arnould, on behalf of the co-authors 
Wilhem Kirch

Editor-in-chief, Journal of Public Health

Ref: Ms. No. JOPH-D-09-00070, "The impact of herpes zoster and subsequent chronic pain on patients' daily lives"

Dear Editor,

Thank you and the reviewers for your feedback on our manuscript, "The impact of herpes zoster and subsequent chronic pain on patients' daily lives".

Attached is our revised manuscript based on the reviewers' comments: we joined a version of the manuscript with track changes, and the manuscript with these changes accepted. Below we provide our point-by-point responses to these comments.

\section{Reviewer \#1:}

"Herpes zoster and the painful complication PHN have a severe impact on patient's quality of life. Due to the actual discussion on the prophylaxis of VZV, I really sympathize with this very good review of the literature. Although the mass of information provided is difficult to digest, it is really helpful for the present discussion. This manuscript helps to have hard data in a subject which we already seem to know; this review puts the focus on the complications caused by VZV and their impact on patients' daily lives.

I recommend to accept the paper and see no need for a revision."

We have slightly restructured the manuscript and added section titles. This will likely facilitate the reading of this dense manuscript.

\section{Reviewer \#2:}

"The authors investigate the impact of zoster and pain following virus infection on patient's daily activities using international database search. The abstract and article selection process is described sufficiently. In addition to this method two models were calculated (description and causal model). As results the authors outline domains and general concepts corresponding to 
references identified by a simple figure (for descriptive model). The same method is used for the so-called causal model. The results obtained are not unexpected. In terms of discussion and conclusion the reviewer is missing the central threat:

1. "The line of thoughts is jumping a little bit around from one subject to another (e. g. page $9 / 10$ row 18-34 and row 1-4 clearly is a repetition of point 'Assessment of evidence level and development of the causal model'). Therefore it should be cancelled."

As suggested, we removed the lines that were a repetition of "Assessment of evidence level and development of the causal model".

In parallel, we restructured this paragraph in order to better outline the points of discussion and to avoid repetitions with the "Methods" section.

2. "Moreover, a part of discussion is dealing with limitations (e. g. quality of life, page 10, row 513). In general, this explanation is correct, but the position should be placed at the beginning or at the end."

We placed the section about quality of life at the end of the "Discussion and conclusion" section, as advised.

3. "The term 'pain' is discussed on page 10 row 15-34. This thoughts are interrupted by 'unmet need' from row 8-13 and direct costs and so on. On row 15 the authors repeatedly are discussing the issue 'pain'."

We restructured this part of the manuscript in order to keep and discuss only the concepts and associations that were identified in the descriptive and causal models.

In addition, in regards to the reviewer's concern about the length of the manuscript, we removed lines throughout this part (Page 10, lines 17-29; page 11, lines 2-4, 9-12) and relocate them in the "Results" section, where they support and facilitate the reading of the figures that are proposed. Also, we have made some changes: the revised discussion is now structured so that there is a brief introduction and summary of what has been done during the work, the rationale and the main result (Page 9, lines 3-21); then the place of 'pain' and the other concepts identified in the descriptive model and the impact represented in the causal model (Page 9, lines 23-32; page 10, lines 1-9); pain and therapeutic strategy (Page 10, lines 11-24); the instruments available (Page 10, lines 26-34); the additional research that should be done and the main limitation of the work (Page 11, lines 1-19). We hope this will help the reader to get to the critical points of the work more easily.

4. "Finally, to make a long story short: The discussion should be outlined more systemically especially in terms of separation between methodological and specialized issues. Redundancies should be eliminated. Regardless of the critical points the manuscript should be shortened substantially." 
As suggested, we shortened the manuscript, especially the "Discussion" section (initially, 1,500 words; currently: 1,000 words) where redundancies have been removed. We restructured the paragraphs of the discussion and relocated result parts in its respective section to better outline and highlight the critical points. We have added titles in the "Methods" and "Results" sections, which should also contribute to a higher clarity and ease of reading.

We took into consideration the points raised above and revised the manuscript accordingly to reinforce the comprehension and strength of the paper and its discussion, and to shorten it to help readers go to the point.

We hope that the revisions and answers to your questions and comments meet your expectations, and that you will consider our revised manuscript for publication. Should you need more information or have question, please do not hesitate to contact us.

Yours sincerely,

Benoit Arnould, on behalf of the co-authors 
1 Title: The impact of herpes zoster and subsequent chronic pain on patients' daily lives 2

3 Authors:

4 Benoit Arnould $^{(1)}$, Khadra Benmedjahed ${ }^{(1)}$, Jean-Luc Gallais ${ }^{(2)}$, Patrick Giniès ${ }^{(3)}$, Ralf 5 Baron $^{(4)}$

6

7 (1) Mapi Values, Lyon, France (2) Medical practice, Paris, France (3) Saint Eloi Hospital,

8 Montpellier, France (4) Division of Neurological Pain Research and Therapy, Department of

9 Neurology, University Hospital, Schleswig-Holstein, Germany

10

11 Corresponding Author:

12 Benoit Arnould

13 Mapi Values

$14 \quad 27$ rue de la Villette

1569003 Lyon

16 France

17 Telephone: +33(0)4 72136953

18 Fax: +33 (0)4 72135140

19 Email: benoit.arnould@ mapivalues.com

20

21 Category: Original Article 


\section{Blinded Manuscript}

Click here to view linked References

1 Title: The impact of herpes zoster and subsequent chronic pain on patients' daily lives

1

22

54

75

8

10

11

12

13

14

15

16

17

18

19

20

21

22

23

24

25

26

27

28

29

30

31

32

33

34

35

36

37

38

39

40

41

42

43

44

45

46

47

48

49

50

51

52

53

54

55

56

57

58

59

60

61

62

63

64

65

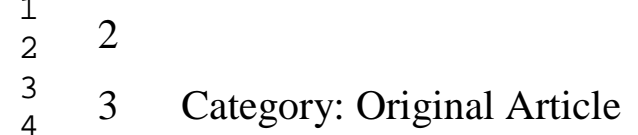

33 Category: Original Article

5 


\section{Abstract}

4 Aim: The aim of our study was to carry out a literature review and develop a model

5 illustrating the domains of patients' lives that are impacted by herpes zoster (HZ) and

6 subsequent chronic pain.

Subject and Methods: Biomedical databases and online congress archives were searched using keywords related to $\mathrm{HZ}$ or post-herpetic neuralgia (PHN) and social, psychological or physical impact. 733 abstracts were reviewed. 29 publications containing concepts reported by patients were retained for the model. Wilson and Cleary's Model was used to organise the findings. Links between concepts were documented on three levels; hypothesis, observation and evidence. The final model illustrates the concepts impacted by $\mathrm{HZ}$ and PHN, relationships between these concepts and the level of evidence identified.

Results: The concepts identified from the articles were grouped into the following categories:

Biological/Physiological, Symptom Status, Functional Status, Health Perceptions,

\section{Characteristics of the Individual, Health-Related Quality of Life (HRQOL), Treatment and}

Characteristics of the Environment. Evidence exists that HZ-related pain directly impacts Functional Status, Health Perceptions and HRQOL.

Conclusion: Patients report that all major domains of life are impaired by $\mathrm{HZ}$ or subsequent chronic pain. $\mathrm{HZ}$ and its painful and debilitating complications can have a substantial impact on physical, psychological, social and role functioning, HRQOL and activities of daily living. The impact on elderly patients needs to be further assessed with appropriately designed and validated instruments, with specific attention paid to dependence.

Keywords: Pain, Herpes Zoster, Post-herpetic Neuralgia, Quality of Life, Patient-Reported Outcomes, Conceptual Model 
3

\section{Introduction}

4 After primary infection with chickenpox, usually during childhood, the varicella zoster virus 5 (VZV) becomes latent. Its reactivation causes herpes zoster (HZ), characterised by a painful vesicular rash and associated with substantial discomfort. It is often accompanied by spontaneous burning pain, parasthesias, itch and allodynia (Binder et al., 2008; Dwyer and Cunningham, 2002; Fields et al., 1998; Schmader and Dworkin, 2008). HZ is a common illness, with an estimated lifetime incidence of 20 to 30\% (Brisson and Edmunds, 2003; Gauthier et al., 2008; Hope-Simpson, 1965; Schmader, 2001). Its prevalence rises with age (Chapman et al., 2003; Gauthier et al., 2008; Bowsher, 1999) ; the lifetime risk is estimated to increase to $50 \%$ in those aged $>85$ years (Miller et al., 1993; Schmader, 2001).

$\mathrm{HZ}$ can be associated with serious complications including post-herpetic neuralgia (PHN), encephalitis, HZ ophthalmicus, facial nerve paralysis, VZV retinitis, cornea affection and glaucoma (Dworkin et al., 2007; Oxman, 2000; Schmader and Dworkin, 2008).

While PHN is the most frequent complication (Dworkin et al., 2007; Johnson, 2001; Wareham and Breuer, 2007), its true incidence remains difficult to determine due to different definitions, methodologies and study populations. PHN persisting at 3 months after rash onset may occur in 10-20\% of HZ patients aged over 50 years (Gauthier et al., 2008; Johnson and Rice, 2007; Oxman et al., 2005; Scott et al., 2006). The incidence of PHN also increases with age (Bowsher, 1999; Goh and Khoo, 1997).

Patient-Reported Outcomes (PROs) can provide valuable data regarding the impact of disease as perceived by patients themselves. The term PRO refers to any health-related data collected directly from the patient (Acquadro et al., 2003). These measures are increasingly used in clinical research (Marquis et al., 2006) (Patrick et al., 2007) and are recognised as a way of reliably and validly assessing symptoms such as pain, functional limitations and health-related quality of life (HRQOL) to supplement standard clinical and physiological criteria (Schipper, 1990; Spilker, 1990; Wilson and Cleary, 1995).

The patients' perspective is recognised as particularly relevant in painful conditions (Committee for Medicinal Products for Human Use, 2007); it is acknowledged that painful chronic conditions are a major cause of impaired HRQOL (Vetter, 2007). The level of pain 
1 experienced by patients with HZ or PHN can be very high (Schmader et al., 2007), and thus is 2 likely to impact patients' daily lives, especially in the elderly. As existing treatments do not 3 adequately control pain in a large proportion of patients (Wu and Raja, 2008; Rowbotham and 4 Petersen, 2001) the assessment of disease burden is particularly interesting in this population. 5

6 The aim of this study was to systematically review the published research on the impact of $7 \quad \mathrm{HZ}$ and PHN, from the patients' perspective. The specific objectives of the work were to: 1) 8 list all domains of patients' lives reported as impaired by $\mathrm{HZ}$ and PHN, 2) identify the 9 hypothesised relationships between these domains; 3) assess the level of published evidence 10 supporting the causality of $\mathrm{HZ}$ and PHN in these impairments. 


\section{Methods}

3 Systematic literature review

4 Information sources

5 The search was conducted in March 2007, exploring MEDLINE, EMBASE and PsycINFO,

6 and the Mapi Research Trust's database of publications on PROs (http://www.mapi-

7 trust.org/); International Society for Pharmacoeconomics and Outcomes Research (ISPOR)

8 and International Society for Quality of Life Research (ISOQOL) abstracts from 2004 to 92006.

10 Search strategy

11 Search criteria were defined as follows: articles written in English and including an abstract, 12 published since 1980 and reporting on the adult population. The searches were carried out using a combination of the following Medical Subject Headings (MeSH): herpes zoster, postherpetic neuralgia, quality of life, psychological adaptation, pain measurement, activities of daily living, patient satisfaction, health status and cost of illness, and the following nonMeSH keywords: functioning, conceptual framework, and impact social, dependence, symptoms and instrumental activities of daily living.

\section{$\underline{\text { Abstract selection }}$}

Selection and rejection criteria were determined as follows: abstracts were retained if they mentioned either PRO concepts related to the impact of HZ, PHN or neuropathic pain on patients' lives, or questionnaires measuring patients' perspectives on these impacts. Abstracts reporting environmental or patient characteristics related to the occurrence, frequency or severity of $\mathrm{HZ}$ or PHN were also retained. Abstracts were rejected if they were not specific to HZ, PHN or neuropathic pain, if only clinical pain was described, or if the study presented did not mention PRO concepts or questionnaires. Seven hundred and thirty-three abstracts were retrieved and reviewed by two researchers independently. Abstracts were selected when an agreement between them was reached. Six hundred and thirty-six abstracts did not meet the selection criteria, or met one of the rejection criteria and were rejected.

\section{Article selection}

Ninety-seven articles were ordered and reviewed in detail. Sixty-eight articles were rejected for one of the following reasons: the target population was not clearly defined, concepts impacted by HZ or PHN were not mentioned, or the studies did not include instruments measuring the impact of $\mathrm{HZ}$ or PHN on patients. 
1 Twenty-nine articles were selected for inclusion in the models. Relevant data from the final 2 set of articles selected was recorded in specific extraction tables. From each article, detailed 3 information was retained on the aim of the study, the population, the country, the 4 questionnaires used and the PRO concepts.

\section{Development of the models}

The information extracted from the selected articles was used to develop two models about the impact of HZ and PHN on patients' lives: a first one providing an organised summary of all concepts identified - this is the descriptive model - and a second one showing only published evidence on causal relationships between these concepts - this is the causal model.

\section{Selection of concepts and development of the descriptive model}

The data extracted from the articles was used to develop a comprehensive model illustrating the impact of HZ and PHN on patients' lives. Wilson and Cleary's model (Wilson and Cleary, 1995) was taken as a basis for the structure of our models. The model developed by Wilson and Cleary contains 5 central domains that are likely to be impacted by a disease or disorder: Biological and Physiological Variables, Symptom Status, Functional Status, General Health Perceptions and Overall Quality of Life. In addition to these, factors which can influence the impact of disease on patients' lives are grouped in two other general domains: Characteristics of the Individual, and Characteristics of the Environment. All of the PRO concepts identified in the selected articles were organised according to these domains to develop a specific descriptive model of $\mathrm{HZ}$ and PHN. One specific new domain - Treatment - was added in order to complete the picture.

\section{Assessment of evidence level and development of the causal model}

The causal relationship between the concepts was then studied at three levels of evidence: tested hypothesis, observed information, or hypothesis. Causal relationships supported by positive statistical testing of predefined hypotheses that were listed among the study objectives were categorised as tested hypothesis; other causal relationships supported by the study data (correlations or tests) were categorised as observed information; and causal relationships mentioned in the introduction or discussion of the article, but not supported by the study data, were categorised as hypotheses. The causal model that was then developed to illustrate the relationships includes only the domains and concepts for which the highest level of evidence (tested hypothesis) was identified in the form of results from a population-based study. 


\section{Results}

4 The PRO questionnaires that were referenced in the publications included in the review can

5 be found in Table 1. The questionnaires are listed according to the domains measured which are: Characteristics of the Individual, Symptom Status, Functional Status, Health Perceptions, Characteristics of the Environment, and QOL. The publications in which these questionnaires were cited or used are referenced in the table.

- Here Table 1 -

\section{Descriptive model}

The model details the concepts identified from the literature search, irrespective of the level of evidence provided by the authors. It is organised into 8 distinct domains: Characteristics of the Individual, Biological/Physical, Symptoms Status, Functional Status, Health Perceptions, Characteristics of the Environment, HRQOL and Treatment. Each domain contains a number of general concepts identified in the referenced articles. Figure 1 is the descriptive model of all of these domains and general concepts. Symptoms associated with HZ and PHN comprised pain, rash, cutaneous manifestations, fever and discomfort. Beyond these symptoms, HZ and PHN had negative effects on physical functioning, activities of daily living, psychological and social functioning, including well-being (van Seventer et al., 2006), depression (Katz et al., 2004), social isolation and withdrawal (Mauskopf et al., 1994; Schmader, 1999).

\section{- Here Figure 1 -}

\section{Causal model}

When the relationship between the different domains was studied in detail, the domains found to be directly impacted by HZ pain and PHN were: Functional Status (Katz et al., 2004; Lydick et al., 1995; Mauskopf et al., 1994; van Seventer et al., 2006), Health Perceptions (van Seventer et al., 2006) and HRQOL (Chidiac et al., 2001; Katz et al., 2004; Lydick et al., 1995; Mauskopf et al., 1994; Schmader, 1999; van Seventer et al., 2006). Figure 2 is the model illustrating these relationships. Functional Status contains basic functions such as sleep and physical mobility, directly impacted by HZ pain and PHN. It also includes Physical Function, which is affected to the extent of interfering with activities of daily living. Health Perceptions is affected in terms of the Health Status of patients. HRQOL comprises complex concepts 


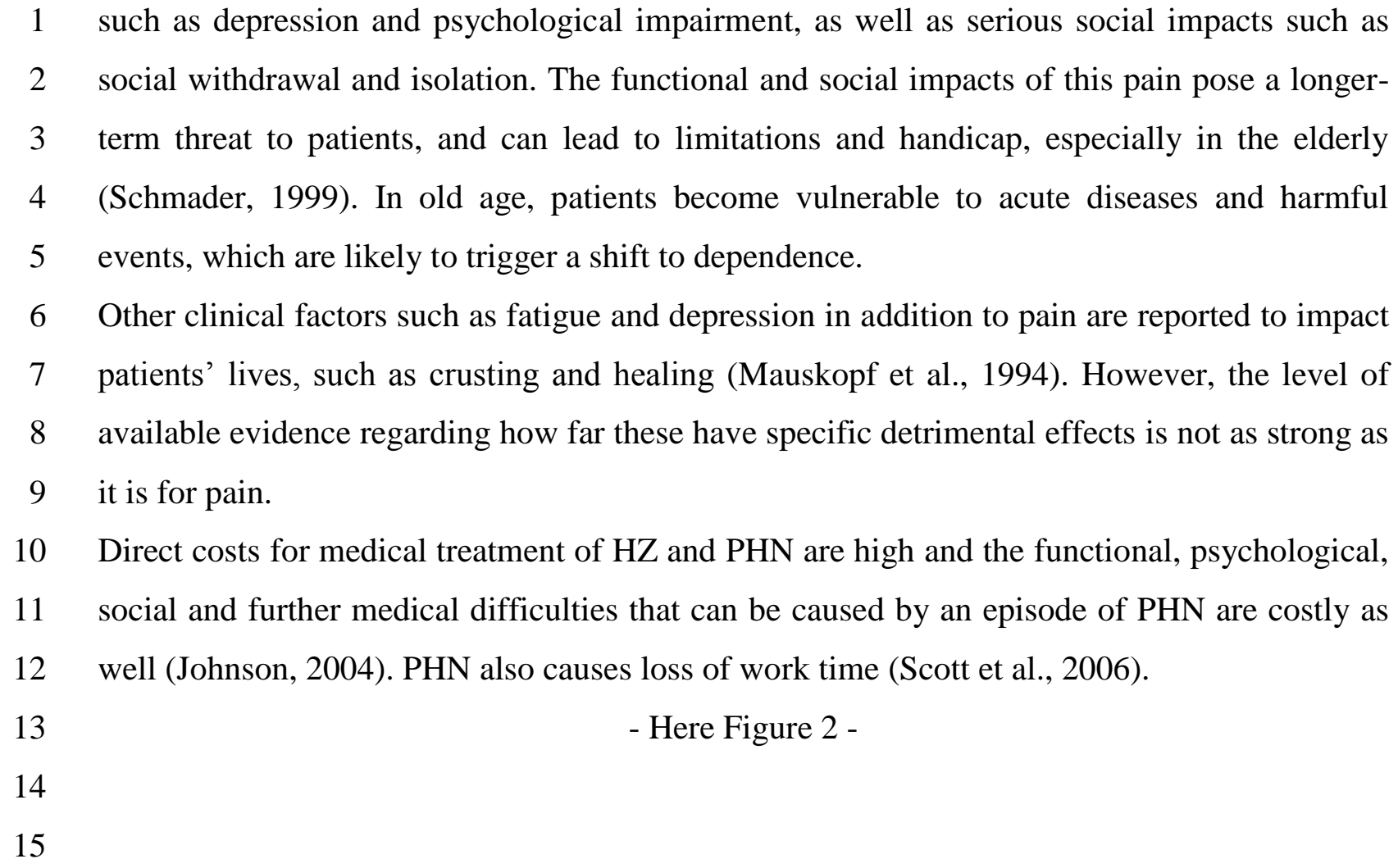

1 such as depression and psychological impairment, as well as serious social impacts such as 2 social withdrawal and isolation. The functional and social impacts of this pain pose a longer3 term threat to patients, and can lead to limitations and handicap, especially in the elderly 4 (Schmader, 1999). In old age, patients become vulnerable to acute diseases and harmful 5 events, which are likely to trigger a shift to dependence.

6 Other clinical factors such as fatigue and depression in addition to pain are reported to impact 7 patients' lives, such as crusting and healing (Mauskopf et al., 1994). However, the level of 8 available evidence regarding how far these have specific detrimental effects is not as strong as 9 it is for pain.

10 Direct costs for medical treatment of $\mathrm{HZ}$ and PHN are high and the functional, psychological, 11 social and further medical difficulties that can be caused by an episode of PHN are costly as 12 well (Johnson, 2004). PHN also causes loss of work time (Scott et al., 2006). 


\section{Discussion and Conclusions}

3 With the rapid expansion of the elderly population in Western countries (Giannakouris, 2008),

4 the prevalence of $\mathrm{HZ}$ is expected to continue to rise, and public health policies must be adapted to the actual severity of these conditions.

A literature review is not experimental research. During the process of accessing sources, selecting articles, extracting the useful information, and organising it, various biases are likely to occur. In order to optimise the reliability and reproducibility of our findings, we applied a systematic approach at each stage of our work: selection of sources, extraction of data, and analysis. A comprehensive descriptive model and a causal model were developed from the systematic literature review. The level of available evidence in causal model relationships was assessed according to predefined rules that enabled the relationships between the concepts to be categorised as tested hypothesis, observed information or hypotheses. The first model highlighted the impact of $\mathrm{HZ}$ and PHN symptoms on all aspects of the patients' lives. As such, it fits remarkably well with the generic model developed by Wilson and Cleary that describes the relationships between clinical parameters and HRQOL (Wilson and Cleary, 1995). HZ pain and PHN were identified as the trigger of every causal relationship, and the only element of the Symptoms Status domain for which sufficient evidence was identified. The causal model gave evidence of relationships between symptoms status, functional status, health perceptions and HRQOL.

Although HZ and PHN have been less studied from the patients' perspective than other common painful conditions, the scientific literature shows consensus on the impact these conditions have on patients' lives. The critical role of pain in $\mathrm{HZ}$ and PHN is consistent with findings in various other painful diseases and conditions, where pain has been identified as the primary cause of negative effects on several functions (Neumann et al., 2000; Wolfe and Hawley, 1997). With pain episodes that are frequently reported by these patients to be particularly severe, pain is considered the major driver of impairment in functioning, health perceptions, and HRQOL. The descriptive and causal models suggest that the combination of impaired physical, psychological, and social functioning resulting from $\mathrm{HZ}$ and $\mathrm{PHN}$ is likely to have irreversible consequences on patients' lives after a certain age. However, to our 
1 knowledge, no epidemiological data are available on the impact of HZ or PHN episodes on institutionalisation rates or other indicators or measures of dependence.

3 As regards the other non-painful symptoms, even if they have been reported to impact 4 patients' lives, further research needs to be conducted to confirm these assumptions and assess the magnitude of the specific impact non-painful symptoms have on patients' lives.

Economic and epidemiologic data confirm the importance of unmet needs in the current management of HZ and PHN (Johnson et al., 2007). Moreover the economic consequences of these conditions are exacerbated as an episode of PHN can be lengthy: after 1 year, 5\%-10\% of patients still experience pain (Johnson, 1995).

Pain being a lasting symptom in particular of PHN, it is one of the main targets of pharmacologic treatment (Johnson et al., 2008). However, the specific vulnerability of the elderly, for whom temporary dysfunction easily turn into permanent disability, highlights the need for strategies centred not on this specific symptom but on the patient. Recent recommendations for HZ management include broader non-pharmacologic approaches such as social support and patient education (Schmader and Dworkin, 2008) (Wu and Raja, 2008), especially for the elderly (Dworkin et al., 2007). An alternative to therapeutic strategy is prevention and early treatment of $\mathrm{HZ}$ in order to lower the incidence of PHN. The prevention of HZ is expected to reduce the costs associated with HZ and PHN (Cunningham et al., 2008). A HZ vaccine has proven effective in reducing incidence and severity of HZ and PHN, especially in individuals aged > 60 (Oxman and Levin, 2008). Vaccination was also associated with improvements in key patient-reported domains such as a reduced interference with activities of daily living (Gnann, Jr., 2008). Further long-term population-based studies are expected in order to examine the epidemiological impact of these vaccination programmes.

A number of generic and specific PRO questionnaires have been developed, validated and used in clinical research to provide a means of assessing the patient's perspective in various diseases and conditions (Chassany et al., 2002). Only a few specific measures have been developed to assess the impact of $\mathrm{HZ}$ and PHN as perceived by the patients, including the Zoster Brief Pain Inventory (Coplan et al., 2004) and the Zoster Impact Questionnaire (Schmader et al., 2007). However, studies identified in the present analysis often used questionnaires that are not specific to the population or to the disease area being considered. 
1 Specific measurement instruments need to be developed and validated for an adequate,

2 reliable and sensitive assessment of these changes, especially in elderly people.

4 Additional research is needed to complete and consolidate the picture of the detrimental effect 5 of HZ and PHN on patients' lives: first, prospective longitudinal studies are needed to provide 6 estimates of the impact of painful episodes and to quantify how much this impact can be 7 limited with new strategies, such as prevention; and then, the assumption regarding the impact 8 of $\mathrm{HZ}$ and PHN on the level of dependence - an assumption which is strongly supported by 9 the impact models based on published data - needs specific epidemiology studies to be 10 conducted for confirmation and quantification.

12 One limitation that could be raised for this literature review is the approximate labelling, or 13 naming of concepts, and lack of appropriate definitions are a source of confusion that 14 frequently surrounds a number of concepts that are dealt with in the literature; the most 15 common confusion lies in the misuse of the term Quality of Life as an umbrella term for 16 patient-related symptoms, function, HRQOL, and health status, whereas Quality of Life is a 17 specific notion with recognised definitions (Schipper, 1990; Spilker, 1990). Despite our 18 awareness of the risk of confusion in the terms used, the models proposed in the present 19 article provide an organisation of the PRO concepts based on the original terminology used by 20 the authors of the selected publications, even when the concepts were not explicitly defined or 21 illustrated with items showing face validity. 


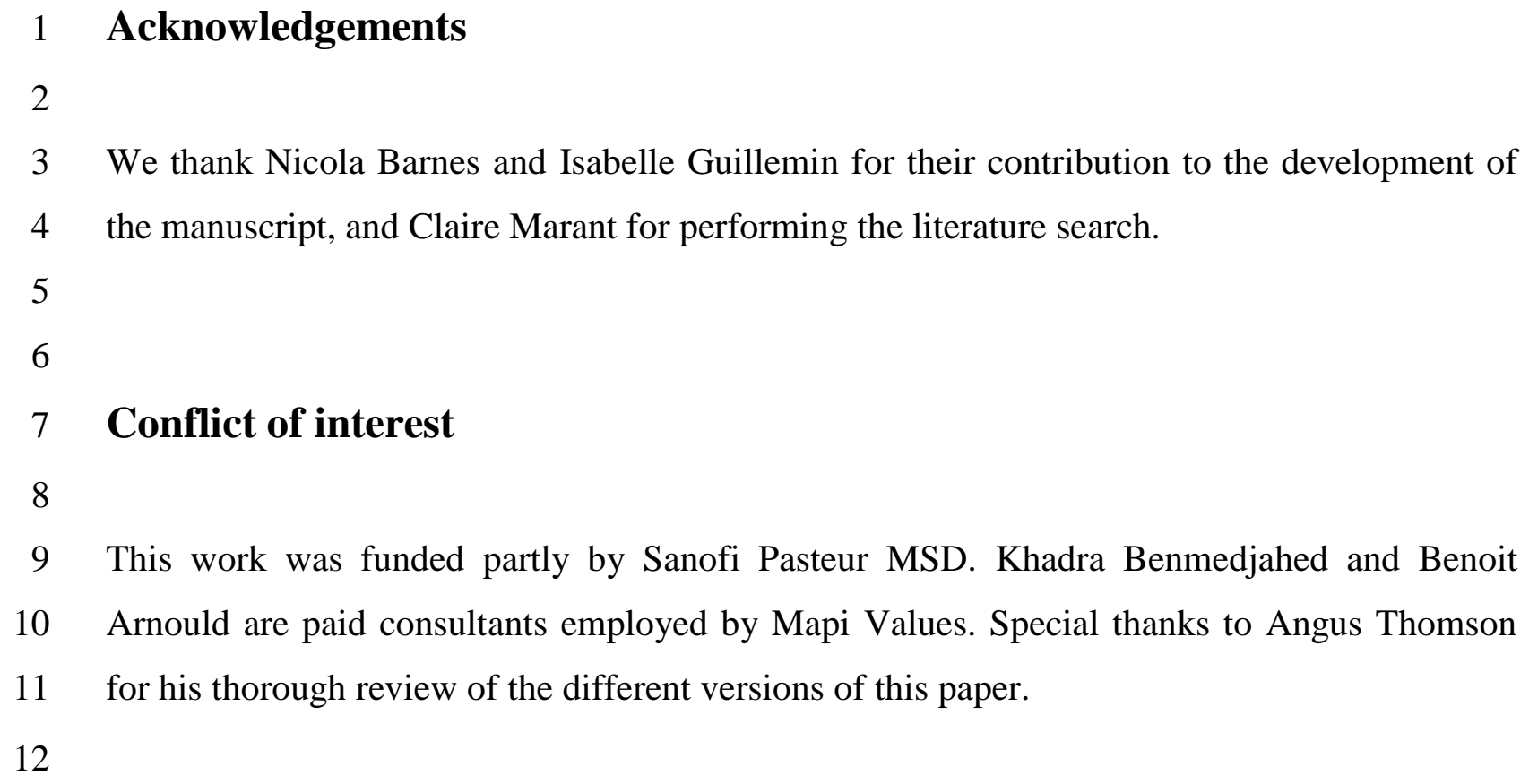


3 Acquadro C, Berzon R, Dubois D, Leidy NK, Marquis P, Revicki D, Rothman M (2003)

4 Incorporating the patient's perspective into drug development and communication: an ad hoc

5 task force report of the Patient-Reported Outcomes (PRO) Harmonization Group meeting at

6 the Food and Drug Administration, February 16, 2001. Value Health 6:522-531

7 Binder A, Koroschetz J, Baron R (2008) Disease mechanisms in neuropathic itch. Nat Clin 8 Pract Neurol 4:329-337

9 Bowsher D (1999) The lifetime occurrence of Herpes zoster and prevalence of post-herpetic 10 neuralgia: A retrospective survey in an elderly population. Eur J Pain 3:335-342

11 Brisson M, Edmunds WJ (2003) Epidemiology of Varicella-Zoster Virus in England and 12 Wales. J Med Virol 70 Suppl 1:S9-14

13 Chapman RS, Cross KW, Fleming DM (2003) The incidence of shingles and its implications 14 for vaccination policy. Vaccine 21:2541-2547

15 Chassany O, Sagnier P, Marquis P, Fullerton S, Aaronson N (2002) Patient-Reported 16 Outcomes: the example of health-related quality of life - a European guidance document for 17 the improved integration of health-related quality of life assessment in the drug regulatory 18 process. Drug Information Journal 36:209-238

19 Chidiac C, Bruxelle J, Daures JP, Hoang-Xuan T, Morel P, Leplege A, El HA, de LC (2001) 20 Characteristics of patients with herpes zoster on presentation to practitioners in France. Clin 21 Infect Dis 33:62-69 
1 Committee for Medicinal Products for Human Use, CHMP (2007) Guideline on clinical

2 medicinal products intended for the treatment of neuropathic pain. Accessed 16 December

32009

4 Coplan PM, Schmader K, Nikas A, Chan IS, Choo P, Levin MJ, Johnson G, Bauer M,

5 Williams HM, Kaplan KM, Guess HA, Oxman MN (2004) Development of a measure of the

6 burden of pain due to herpes zoster and postherpetic neuralgia for prevention trials: adaptation

7 of the brief pain inventory. J Pain 5:344-356

8 Cunningham AL, Breuer J, Dwyer DE, Gronow DW, Helme RD, Litt JC, Levin MJ,

9 Macintyre CR (2008) The prevention and management of herpes zoster. Med J Aust 188:171-

$10 \quad 176$

11 Dworkin RH, Johnson RW, Breuer J, Gnann JW, Levin MJ, Backonja M, Betts RF, Gershon

12 AA, Haanpaa ML, McKendrick MW, Nurmikko TJ, Oaklander AL, Oxman MN, Pavan-

13 Langston D, Petersen KL, Rowbotham MC, Schmader KE, Stacey BR, Tyring SK, van Wijck

14 AJ, Wallace MS, Wassilew SW, Whitley RJ (2007) Recommendations for the management of

15 herpes zoster. Clin Infect Dis 44 Suppl 1:S1-26

16 Dwyer DE, Cunningham AL (2002) 10: Herpes simplex and varicella-zoster virus infections.

17 Med J Aust 177:267-273

18 Fields HL, Rowbotham M, Baron R (1998) Postherpetic neuralgia: irritable nociceptors and

19 deafferentation. Neurobiol Dis 5:209-227

20 Gauthier A, Breuer J, Carrington D, Martin M, Remy V (2008) Epidemiology and cost of 21 herpes zoster and post-herpetic neuralgia in the United Kingdom. Epidemiol Infect 1-10 
1 Giannakouris, K (2008) Ageing characterises the demographic perspectives of the European

2 societies. Accessed 16 December 2009

3 Gnann JW, Jr. (2008) Vaccination to prevent herpes zoster in older adults. J Pain 9:S31-S36

4 Goh CL, Khoo L (1997) A retrospective study of the clinical presentation and outcome of

5 herpes zoster in a tertiary dermatology outpatient referral clinic. Int J Dermatol 36:667-672

6 Hope-Simpson RE (1965) The Nature of Herpes Zoster: A Long-term Study and a New

7 Hypothesis. Proc R Soc Med 58:9-20

8 Johnson R (2001) Herpes zoster--predicting and minimizing the impact of post-herpetic

9 neuralgia. J Antimicrob Chemother 47 Suppl T1:1-8

10 Johnson RW (1995) The future of predictors, prevention, and therapy in postherpetic

11 neuralgia. Neurology 45:S70-S72

12 Johnson RW (2004) Pain following Herpes Zoster: Implications for Management. HZ Pain

13 Management 11:3:63-65

14 Johnson RW, Rice AS (2007) Pain following herpes zoster: the influence of changing

15 population characteristics and medical developments. Pain 128:3-5

16 Johnson RW, Wasner G, Saddier P, Baron R (2007) Postherpetic neuralgia: epidemiology,

17 pathophysiology and management. Expert Rev Neurother 7:1581-1595

18 Johnson RW, Wasner G, Saddier P, Baron R (2008) Herpes zoster and postherpetic neuralgia:

19 optimizing management in the elderly patient. Drugs Aging 25:991-1006

20 Katz J, Cooper EM, Walther RR, Sweeney EW, Dworkin RH (2004) Acute pain in herpes

21 zoster and its impact on health-related quality of life. Clin Infect Dis 39:342-348 
1 Lydick E, Epstein RS, Himmelberger D, White CJ (1995) Area under the curve: a metric for

2 patient subjective responses in episodic diseases. Qual Life Res 4:41-45

3 Marquis P, Arnould B, Acquadro C, Roberts WM (2006) Patient-Reported Outcomes and

4 Health-Related Quality of Life in Effectiveness Studies: Pros and Cons. Drug Development

5 Research 67:193-201

6 Mauskopf J, Austin R, Dix L, Berzon R (1994) The Nottingham Health Profile as a measure

7 of quality of life in zoster patients: convergent and discriminant validity. Qual Life Res 3:431-

$8 \quad 435$

9 Miller E, Marshall R, Vurdien J (1993) Epidemiology, outcome and control of varicella-

10 zoster infection. Reviews in Medical Microbiology 4:222-230

11 Neumann L, Berzak A, Buskila D (2000) Measuring health status in Israeli patients with 12 fibromyalgia syndrome and widespread pain and healthy individuals: utility of the short form

13 36-item health survey (SF-36). Semin Arthritis Rheum 29:400-408

14 Oxman MN (2000) Clinical manifestations of Herpes Zoster. In: Arvin A, Gershon AA (eds)

15 Varicella-Zoster Virus. Virology and clinical management, Cambridge University Press,

16 Cambridge, pp 246-275

17 Oxman MN, Levin MJ (2008) Vaccination against Herpes Zoster and Postherpetic Neuralgia.

18 J Infect Dis 197 Suppl 2:S228-S236

19 Oxman MN, Levin MJ, Johnson GR, Schmader KE, Straus SE, Gelb LD, Arbeit RD, 20 Simberkoff MS, Gershon AA, Davis LE, Weinberg A, Boardman KD, Williams HM, Zhang 21 JH, Peduzzi PN, Beisel CE, Morrison VA, Guatelli JC, Brooks PA, Kauffman CA, Pachucki 22 CT, Neuzil KM, Betts RF, Wright PF, Griffin MR, Brunell P, Soto NE, Marques AR, Keay 
1 SK, Goodman RP, Cotton DJ, Gnann JW, Jr., Loutit J, Holodniy M, Keitel WA, Crawford

2 GE, Yeh SS, Lobo Z, Toney JF, Greenberg RN, Keller PM, Harbecke R, Hayward AR, Irwin

3 MR, Kyriakides TC, Chan CY, Chan IS, Wang WW, Annunziato PW, Silber JL (2005) A

4 vaccine to prevent herpes zoster and postherpetic neuralgia in older adults. N Engl J Med

$5 \quad 352: 2271-2284$

6 Patrick DL, Burke LB, Powers JH, Scott JA, Rock EP, Dawisha S, O'Neill R, Kennedy DL

7 (2007) Patient-reported outcomes to support medical product labeling claims: FDA

8 perspective. Value Health 10 Suppl 2:S125-S137

9 Rowbotham MC, Petersen KL (2001) Zoster-associated pain and neural dysfunction. Pain $10 \quad 93: 1-5$

11 Schipper H (1990) Guidelines and caveats for quality of life measurement in clinical practice 12 and research. Oncology (Williston Park) 4:51-57

13 Schmader K (1999) Herpes zoster in the elderly: issues related to geriatrics. Clin Infect Dis $14 \quad 28: 736-739$

15 Schmader K (2001) Herpes zoster in older adults. Clin Infect Dis 32:1481-1486

16 Schmader K, Dworkin RH (2008) Natural History and Treatment of Herpes Zoster. The 17 Journal of Pain 9:S3-S9

18 Schmader KE, Sloane R, Pieper C, Coplan PM, Nikas A, Saddier P, Chan IS, Choo P, Levin 19 MJ, Johnson G, Williams HM, Oxman MN (2007) The impact of acute herpes zoster pain and 20 discomfort on functional status and quality of life in older adults. Clin J Pain 23:490-496

21 Scott FT, Johnson RW, Leedham-Green M, Davies E, Edmunds WJ, Breuer J (2006) The 22 burden of Herpes Zoster: a prospective population based study. Vaccine 24:1308-1314 
1 Spilker B (1990) Introduction to the Field of Quality of Life Trials. In: Spilker B (ed) Quality

2 of Life Assessments in Clinical Trials, Raven Press, New York, pp 3-10

3 van Seventer R, Sadosky A, Lucero M, Dukes E (2006) A cross-sectional survey of health

4 state impairment and treatment patterns in patients with postherpetic neuralgia. Age Ageing $5 \quad 35: 132-137$

6 Vetter TR (2007) A primer on health-related quality of life in chronic pain medicine. Anesth

$7 \quad$ Analg 104:703-718

8 Wareham DW, Breuer J (2007) Herpes zoster. BMJ 334:1211-1215

9 Wilson IB, Cleary PD (1995) Linking clinical variables with health-related quality of life. A 10 conceptual model of patient outcomes. JAMA 273:59-65

11 Wolfe F, Hawley DJ (1997) Measurement of the quality of life in rheumatic disorders using 12 the EuroQol. Br J Rheumatol 36:786-793

13 Wu CL, Raja SN (2008) An update on the treatment of postherpetic neuralgia. J Pain 9:S19$14 \quad \mathrm{~S} 30$ 


\section{Legends for Figures}

2

3 Figure 1. Descriptive model: domains, general concepts and their references identified in

4 relation to $\mathrm{HZ}$ and PHN. The figure is based on Wilson and Cleary's model, but does not

5 illustrate causal relationships.

6

7 Figure 2. Causal model: the patient-reported impact of HZ pain and PHN. Arrows indicate 8 direction of causal relationship.

9 
Table 1. PRO questionnaires identified in literature review

\begin{tabular}{|c|c|}
\hline Domain & Instrument \\
\hline $\begin{array}{l}\text { Characteristics of the } \\
\text { Individual }\end{array}$ & $\begin{array}{l}\text { Charlson Comorbidity Index - Lydick E, } 1995 \\
\text { Coping Strategies Questionnaire (CSQ) -Haythtornthwaite JA, } 2003 \\
\text { Dysfunctional Attitude Scale (DAS) - Dworkin RH, } 1992 \\
\text { Illness Behaviour Questionnaire (IBQ) - Dworkin RH, } 1992 \text {; Katz J, } 2005 \\
\text { Multidimensional Health Locus of control (MHLC) - Katz J, 2005 } \\
\text { National Institute of Mental Health Diagnostic Interview Schedule (NIMH DIS) -Clark MR, } 2000 \\
\text { Pain Catastrophizing Scale (PCS) - Sullivan MJL, } 2005 \\
\text { Personality Disorder Questionnaire (PDQ) - Katz J, } 2004 \text {; Katz J, 2005 } \\
\text { Spielberger State Trait Anxiety Inventory (STA) - Dworkin RH, 1992; Katz J, } 2004 \text {; Katz J, } 2005 \\
\text { Somatic Symptom Index - Katz J, 2005 } \\
\text { Somatosensory Amplification Scale - Katz J, } 2005\end{array}$ \\
\hline Symptoms Status & $\begin{array}{l}\text { Wisconsin Brief Pain Inventory (BPI) - Lydick E, } 1995 \\
\text { Modified Short Form Brief Pain Inventory (mBPI-SF) - Van Seventer R, } 2006 \\
\text { Gracely scales - Mauskopf J, } 1994 \\
\text { Items on PHN pain intensity - Oster G, } 2004 \\
\text { MOS Pain Index - Katz J, } 2004 \text {; Katz J, } 2005 \\
\text { Mc Gill Pain Questionnaire (MPQ) - Dworkin RH, } 1992 \text {; Katz J, } 2004 \\
\text { Short-form Mc Gill Pain Questionnaire (MPQ-SF) - Farrell MJ, } 1995 \text {; Sullivan MJL, } 2005 \\
\text { Numerical Rating Scale for Pain - Haythorthwaite, } 2003 \\
\text { West Haven-Yale Multidimensional Pain Inventory (WHYMP) - Haythornthwaite JA, } 2003 \\
\text { Zoster Brief Pain Inventory (ZBPI) - Available in appendix of Coplan PM, 2004 ; Scott FT, } 2006\end{array}$ \\
\hline Functional Status & $\begin{array}{l}\text { 6-point scale measuring the effect of pain on patients' ability to perform ADL - Mauskopf J, } 1994 \\
\text { Human Activity Profile (HAP) - Farrell MJ, } 1995 \\
\text { Pain Disability Index (PDI) - Sullivan MJL, } 2005 \\
\text { Zoster Brief Pain Inventory (ZBPI) - Coplan PM, } 2004 \text {; Scott FT, } 2006\end{array}$ \\
\hline Health Perceptions & $\begin{array}{l}\text { 100-point global health rating scale - Oster G, } 2004 \\
\text { Self-reported overall health rating, and health resource utilisation - Van Seventer, } 2006\end{array}$ \\
\hline $\begin{array}{l}\text { Characteristics of the } \\
\text { Environment }\end{array}$ & $\begin{array}{l}\text { Geriatric Scale of Recent Life Events (GSRLE) - Schmader K, } 1990 \text {;Schmader K, } 1998 \\
\text { Life Stressors and Social Resources Inventory (LSSRI) - Katz J, } 2005 \\
\text { Schedule of Recent Experience (SRE) - Dworkin RH, } 1992\end{array}$ \\
\hline Quality of Life & $\begin{array}{l}\text { Beck Depression Inventory (BDI) - Dworkin RH, } 1992 \text {; Katz J, } 2004 \text {; Katz J, } 2005 \\
\text { Geriatric Depression Scale (GDS) - Farrell MJ, } 1995 \\
\text { EQ-5D - Oster G, } 2004 \text {; Scott FT, } 2006 \text {; Van Seventer R, } 2006 \\
\text { Hospital Anxiety and Depression (HAD) - Scott FT, } 2006 \\
\text { Life Satisfaction in the Elderly Scale (LSES) - Dworkin RH, } 1992 \\
\text { Mental Health Inventory (MHI) - Katz J, 2004 ; Katz J, } 2005 \\
\text { Nottingham Health Profile (part 1) (NHP) - Mauskopf J, } 1994 \text {; Meyer-Eosberg K, } 2001 \\
\text { Hopkins symptom checklist 90-R(SCL-90-R) - Clark MR, } 2000 \\
\text { SF-36 - Chidiac C, } 2001 \text {; Katz J, 2004 ; Katz J, } 2005 \text {; Lydick E, } 1995 \text {; Meyer-Eosberg K, } 2001 \\
\text { Social Interaction Scale (SIS) - Schmader K, } 1998 \\
\text { Social Network Scale (SNS) - Schmader K, } 1998\end{array}$ \\
\hline
\end{tabular}




\section{Figure 1.}

\section{CHARACTERISTICS OF THE INDIVIDUAL}

Age(Lydick, 1995; Goh, 1997; Dworkin, 1999; Katz, 2005) Race (Schmader, 1998) Gender (Dworkin, 1999) Personality, Attitudes and Beliefs (Dworkin, 1992; 1999; Katz, 2005; Sullivan, 2005) Behaviour (Goh, 2007; Johnson, 2003; Dworkin, 1992; 1999; Sullivan, 2005; Haythornthwaite, 2003) Comorbidity (Lydick, 1995, Dworkin, 1999; Katz, 2005) Life events (Dworkin, 1992; 1999; Katz, 2005; Schmader, 1990; 1998)

\begin{tabular}{|l|}
\hline \multicolumn{1}{|c|}{ SYMPTOMS STATUS } \\
Pain (Chidiac, 2001; Lydick, \\
1995; Mauskopf, 1994; \\
Portenoy, 1986; Schmader, \\
1990; 1999; 2001; 2002; 2003; \\
Goh, 1997; Van Seventer, 2006; \\
Baron, 2004; Johnson, 2003; \\
Katz, 2004; 2005; Oster, 2004; \\
Scott, 2006; Dworkin, 1992; \\
1999; Farrell, 1995; McCarbreg, \\
2003; Sullivan, 2005; Clark, \\
2000; Haythornthwaite, 2003;) \\
Rash (Lydick, 1995; Katz, \\
2005; Haythornthwaite, 2003) \\
Cutaneous Manifestations \\
(Mauskopf, 1994; Dworkin, \\
1999) \\
Fever (Dworkin, 1999) \\
Discomfort (Goh, 1997) \\
\hline
\end{tabular}

\section{FUNCTIONAL STATUS}

Sleep (Bajwa, 2001; Chidiac, 2001;

Lydick, 1995; Mauskopf, 1994;

Portenoy, 1986; Schmader, 1999;

2001; 2002; 2003; Van Seventer,

2006; Baron, 2004; Goh, 1997;

Johnson, 2003; McCarbreg, 2003)

Physical Functioning (Chidiac,

2001; Lydick, 1995; Mauskopf, 1994;

Portenoy, 1986; Schmader, 2002;

2003; Van Seventer, 2006; Baron,

2004; Goh, 1997; Johnson, 2003;

Katz, 2004; Farrell, 1995;

McCarbreg, 2003; Sullivan, 2005;

Haythornthwaite, 2003)

Physiological

Mechanisms
(Dworkin, 1999)

Cognitive (Schmader, 1999; 2002;

$$
\text { 2003) }
$$

Activities of Daily Living (Lydick 1995; Schmader, 1999; 2001; 2002; 2003; Van Seventer, 2006; Goh, 1997; Dworkin, 1999; McCarbreg, 2003)

\section{TREATMENT}

Abuse of Medical Resources ( Portenoy, 1986)

Drug Dependency (Johnson, 2003)

CHARACTERISTICS OF THE ENVIRONMENT

Home Life (Dworkin, 1999; Katz, 2005; Schmader, 1990; Schmader, 1998; Schmader, 2003)

\section{QUALITY OF LIFE}

Quality of Life (Chidiac, 2001; Lydick, 1995; Mauskopf, 1994; Van Seventer, 2006; Johnson, 2003; Katz, 2004; Scott, 2006; McCarbreg, 2003;

Haythornthwaite, 2003; Meyer-

Eosberg, 2001; Schmader, 2002)

\section{Psychological/Emotional Difficulties} (Bajwa, 2001; Chidiac, 2001; Lydick, 1995; Portenoy, 1986; Schmader, 1998; 1999; 2001; 2002; 2003; Van Seventer, 2006; Baron, 2004; Goh, 1997; Johnson, 2003; Katz, 2004; 2005; Scott, 2006; Dworkin, 1992; 1999; Farrell, 1995; McCarbreg, 2003; Schmader, 1998; Clark, 2000; Haythornthwaite, 2003)

Psychological Functioning (Lydick, 1995; Mauskopf, 1994; Portenoy, 1986; Johnson, 2003; Katz, 2004;

Haythornthwaite, 2003)

Motivation / Satisfaction (Chidiac, 2001; Lydick, 1995; Mauskopf, 1994; Portenoy, 1986; Van Seventer, 2006; Dworkin, 1992; Katz, 2005; Schmader, 2003)

Self-Esteem (McCarbreg, 2003)

Well-being (Van Seventer, 2006; Katz, 2004; 2005; McCarbreg, 2003)

Social Functioning (Chidiac, 2001; Mauskopf, 1994; Portenoy, 1986; Schmader, 1999; 2001; 2002; 2003; Baron, 2004; Johnson, 2003; Katz, 2004; 2005; McCarbreg, 2003;)

Role (Chidiac, 2001; Portenoy, 1986; Schmader, 2002; Katz, 2004; 2005)

Relationships (Lydick, 1995;

Schmader, 2002; Van Seventer, 2006; McCarbreg, 2003) 
Figure 2.

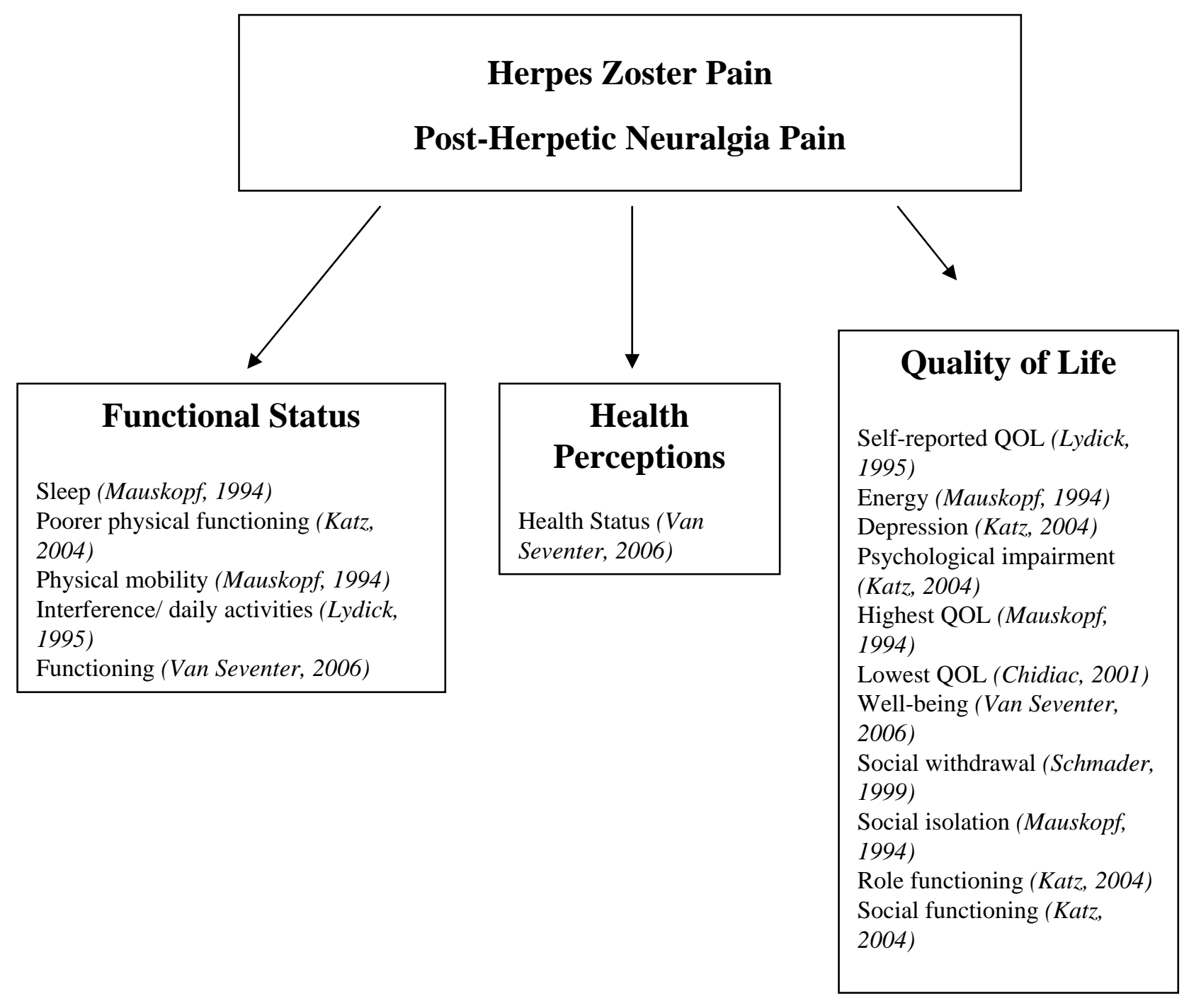


Supplementary Material
Click here to download Supplementary Material: Conflict of interest.doc

Supplementary Material
Click here to download Supplementary Material: Conflict of interest.doc

-

$(2+2$

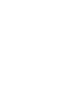

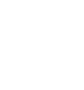

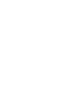

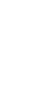
. .

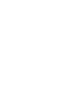
(

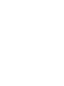

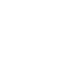

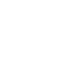

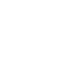

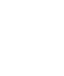

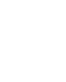
更

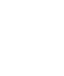

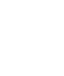

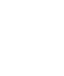

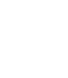

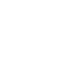

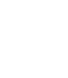

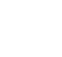

(1) 